\title{
Influencing consumer engagement in online customer communities: The role of interactivity
}

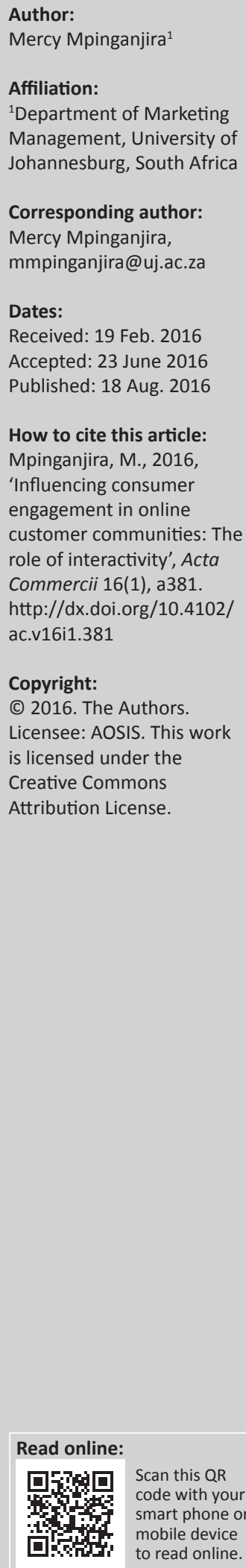

Purpose: The purpose of this article was to investigate consumer engagement in online customer communities and the influence of interactivity on it. A conceptual model linking different dimensions of interactivity and consumer engagement was proposed and tested.

Rationale: The ability of managers to ensure high levels of consumer engagement depends on them gaining a good understanding of the concept, its manifestations in their context, as well as factors that influence it. This article aims at contributing to this understanding in the context of online customer communities.

Methodology: The article followed a quantitative research approach. Data were collected from 303 members of online customer communities based in Gauteng, South Africa. Structural equation modelling was used to test the hypotheses proposed in the article.

Findings and implications: The results showed that system-related dimensions of interactivity and human interactivity are positively associated with consumer psychological engagement. Psychological engagement was in turn found to be positively associated with behavioural engagement. The findings point to the need for managers to pay attention to system and human related interactivity if they are to influence consumer engagement levels on their sites.

Originality and value of research: Little research exists on consumer engagement, resulting in limited understanding of the concept as well as its antecedents. Focusing on online customer communities, this article contributes to addressing this gap in literature. Managers of online customer communities can use the findings to monitor levels of consumer engagement on their sites and find ways of enhancing it.

\section{Introduction}

The concept of 'engagement' is of significant interest to practitioners and researchers in many fields including education, business, political science and psychology (Brodie et al. 2011:254). Dwivedi (2015:101) observed that whilst the notion of engagement has been investigated for some time in the domains of organisational psychology, it is only recently that the concept has emerged as one of great interest in the domain of marketing and consumer behaviour in particular. Brodie et al. (2011:254) traced the initial use of engagement as a term in business practice to an article by Appelbaum (2001:5). Appelbaum (2001:5), writing in an industry business journal, pointed out that research by Gallup, the global consulting company, shows that customer engagement, unlike customer satisfaction, is a better predictor of customer loyalty. Cheung, Lee and Jin (2011:2) observed that in marketing, the concept of engagement has been of particularly high interest amongst practitioners; most of what is written on the topic, is based on practice and not theory and is found in practitioner journals.

The great interest shown by practitioners in understanding consumer engagement is driven by benefits associated with it. Sashi (2012:254) observed that customer engagement is critical to the success of any organisation as it helps to establish intimate bonds in relational exchanges between seller and customer. Sashi (2012:254) further noted that these bonds enable customers to continue relying on a seller not only in terms of transacting with the seller, but also in value co-creation. Commenting on customer value co-creation, Harwood and Garry (2015:533) remarked that contemporary marketing thinking recognises that customers are a source of significant resources, including time and knowledge resources which have direct and indirect effects on firms and other customers. Gambetti and Graffigna (2010:802) remarked that customers in the post-modern society are looking for satisfaction of composite needs, including the need to play more active roles in the consumption process through, for example, contributing to new product development. Satisfaction of the diverse customer needs is critical to the development of competitive advantage. 
Accordingly, Brodie et al. (2013:105) commented that customer engagement represents a strategic imperative for enhanced corporate performance.

Whilst the benefits of engagement are readily articulated in consumer behavioural literature, what exactly constitutes engagement in this domain is a matter that lacks clarity and consensus (Brodie et al. 2013:105; Cheung et al. 2015:242). Brodie et al. (2013:106) attributed the lack of clarity to the fact that very few researchers have attempted to define the concept. Furthermore, significant differences exist in how the concept is viewed by different researchers. One of the widely cited definitions is that by Van Doorn et al. (2010:254) who argued that engagement denotes a behavioural focus, and defined customer engagement as 'behavioural manifestations that have a brand or firm focus beyond purchase, resulting from motivational drivers'. Most consumer behavioural studies take a behavioural perspective in looking at engagement. Whilst this is so, other studies argued that engagement is internal to an individual and thus advocate the need to look at engagement from a psychological perspective. Taking this perspective, Brodie et al. (2011:258) defined customer engagement as 'a psychological state, which occurs by virtue of interactive customer experiences with a focal agent/object within specific service relationships'. In looking at engagement, this article focuses on both the behavioural as well as the psychological forms and argues for the existence of significant relationships between the two forms amongst users of online customer community sites.

Apart from differences in perspectives when it comes to forms of consumer engagement, most of the research undertaken is this area is based on qualitative or descriptive analysis and is not guided by some underlying theory (Cheung et al. 2011:2,3). Furthermore, many studies have taken the interest to examine antecedents of consumer engagement. This article aims at contributing to addressing these research gaps by applying the service-dominant logic (SDL) of marketing to understand consumer engagement in online community sites. The SDL argues for the importance of interactive and co-creative experiences in understanding some behavioural outcomes on the part of consumers (Brodie et al. 2011:253; Vargo \& Lusch 2004:1). Online customer community sites are social media platforms that give customers the opportunity to interact with other customers and share information including problems, and come up with solutions to them. Examples of online customer communities include Play Station Community by Sony, the Harley Owners Group by Harley-Davidson, Being Girl by Procter, and Gamble and Lugnet by Lego. Whilst detailed statistics on line customer community sites are not readily available, Manchanda, Packard and Pattabhiramaiah (2015:368) pointed out that as early as 2011, half of the top 100 global brands were estimated to have their own firmsponsored online customer communities. Manchanda et al. (2015:368) also pointed out that a 2012 research report by Forrester found that at that time, as many as ' 18 percent of all businesses around the world were making online customer community investments independent of third parties'. Cabiddu, De Carlo and Piccoli (2014:176) observed that many firms today are hosting such sites for the purposes of connecting and building relationships with customers, and that many other sites are being established independently by consumers. Not much is, however, known about engagement in such contexts as result of lack of research. By focusing on online customer communities, this article contributes to knowledge on engagement in such contexts.

The main purpose of this article is thus to examine consumer engagement in the context of online customer communities and the role of interactivity in this. The specific objectives of the article are to:

- Examine levels of user psychological and behavioural engagement in online customer communities.

- Investigate the relationship between interactivity in online customer community sites and psychological engagement of users.

- Investigate the relationship between psychological engagement and behavioural engagement.

- Propose and test a conceptual model on the relationship between interactivity, psychological engagement and behavioural engagement.

The article is organised as follows: the next section provides a review of literature including the article's proposed hypotheses and conceptual model. This is followed by a discussion of the research methodology and the presentation of findings respectively. Thereafter, the results are discussed and their theoretical as well as managerial implications outlined. Next is a discussion on limitations of the paper and suggestions for future research before concluding.

\section{Literature review The service-dominant logic}

Proposed by Vargo and Lusch (2004:1), the SDL emphasises the importance of, firstly, service as the fundamental basis of exchange relations; secondly, value as defined by customers and creation of value through interaction; and thirdly, operant resources (knowledge and skills) as fundamental sources of competitive advantage. When it comes to service, of concern in the SDL is the 'process of using one's resources for the benefit of another entity' (Kuzgun \& Asugman 2015:243). Traditionally, as pointed out by Cellary (2015:3630), the application of resources for the benefit of another presupposed that the actors are humans. This is because according to the classic service scenario, service exchange requires physical interaction between the service provider and the recipient of the service.

Developments in technology have, however, changed the way in which service is delivered. Increasing use is being made of electronic technologies to provide service, resulting in a phenomenon called e-service. As noted by Cellary (2015:3631-3633), e-service can be provided remotely through a platform in three main ways. One way is where the main service-providing party is another human who is simply 
using the technology platform to reach out to another human, a customer. Cellary (2015:3631-3633) identified the second scenario where the main service- providing party is software under customer control and the customer interacts with the software as is the case with most self-service technologies, including banking sites. The last scenario identified is where there is a program agent for a service person and the agent is not subject to customer control such as a software agent that selects advertisements in a search engine using business intelligence and data mining techniques. Looking at the different scenarios pointed out in Cellary (2015:3631-3633), service in the context of online community sites involves mainly the first two scenarios, that is human-to-human interaction, as well as software and human interaction where the software is under human control. This is because online communities enable users to interact with other users to share information. In the process of interacting with other users, online customer community members also utilise the website which is subject to their control, as in terms of the ability to direct functions that the site needs to perform.

Cognisant of arguments that engagement occurs as a result of 'interactive customer experiences with a focal agent/object' (Brodie et al. 2011:258) as well as the argument in the SDL that value is interactively created (Vargo \& Lusch 2004:6), this article argues that user engagement in online customer communities can be explained by examining the interactivity of the main service providers associated with online customer communities. That is to say that engagement in online customer community sites may be explained by human interactivity and website interactivity.

On the notion of value, the SDL argues that value is customer defined and co-created (Vargo \& Lusch 2004:11). Commenting on co-creation of value in relation to social media, Kilkku (2011:Online) observed that social media has actually blurred the roles of seller and customer by facilitating engagement and consequently, co-creation. Through shared content on social media platforms such as online customer communities, customers are able to gain information that helps improve their product choice and decision-making in general. Companies on the other hand, gain intelligence that they can use in developing their products and enhance chances of customer satisfaction. As noted by Kilkku (2011:Online), value proposals based on customer input enhance chances of successful products development, whilst at the same time helping customers avoid settling for inferior value proposals because of lack of input.

In looking at value, it is also important to take cognisance of the experiential value associated with the use of online platforms and the role that interactivity can play in this. Studies by Liu et al. (2015:9) as well as Mpinganjira (2014:593), show that high levels of website interactivity as defined by website responsiveness, positively impact on perceived experiential value of users. Human responsiveness on websites has also been found to have positive impact on perceived experiential value on online platforms.
Based on the discussion above, this article argues that the SDL provides a good theoretical basis on which to examine consumer engagement in the context of online customer communities and the role of interactivity.

\section{Consumer engagement}

According to Dovaliene, Masiulyte and Piligrimiene (2015:660) as well as Bordie et al. (2011:259), proper conceptualisation of 'engagement' requires that one takes into account the context of study, particularly the subjects and objects of engagement. The identification of subjects of engagement requires answering the question, 'Who is engaged?' A review of business literature shows that most studies focus on either the consumers of products or services, or the employees of an organisation. Identification of objects of engagement on the other hand, requires answering the question, 'What is engaging?' Examples of objects of engagement would include products, services, brands, advertisements or Internet applications. Differences in objects and subjects of engagement under focus in research studies have resulted in the proliferation of terms carrying the engagement label. Some of the common terms include brand engagement, customer engagement, consumer engagement and user engagement (Hollebeek, Glynn \& Brodie 2014:150). In this article, the object of engagement is the online customer community, inclusive of the platform and other human actors on the platform. The subject of engagement is the individual user of such sites.

With the subject of engagement being users of online customer community sites, of concern in this article are the manifestations of engagement in the users. As noted before, literature shows that consumer engagement can be examined from a behavioural or a psychological perspective. Ángeles Oviedo-García et al. (2014:335) focused on behavioural manifestations of engagement, whilst Bowden (2009:65) focused on psychological manifestations. Chandler and Lusch (2014:9) pointed out that 'there is an urgent need in the service literature to integrate varying conceptualisations in order to account more fully for the influence of context and experience on customer engagement'. Whilst Chandler and Lusch's (2014:9) call was made in the context of subjects of engagement noting the need for researchers to not only focus on customer engagement but also on other subjects including suppliers, manufactures and retailers, this article further argues for the need for more studies that integrate the different manifestations of engagement. In looking at engagement, it thus focuses on both behavioural as well as psychological engagement.

In looking at psychological engagement, the article focuses on users' affective state. Hollebeek (2013:19) identified affective gratification of consumers as an important component of engagement. Hollebeek (2013:19) noted that brands' affective gratification is evidenced by positive feelings experienced when one uses a brand. It examines users' feelings experienced when use is made of their respective online customer community sites. Behavioural 
engagement on the other hand, relates to the application of self to tasks (Chandler \& Lusch 2014:8). In the context of online customer communities, such tasks would include participating in community activities including paying attention to postings on such sites, and the regular provision of suggestions in response to enquiries posted on community sites. The article posits that the two forms of engagement are related. This is in line with findings by Hollebeek et al. (2014:160) which show that customers' affective state exerts positive influence on behavioural responses. Cheung et al. (2015:247), in a study focused on engagement amongst players of online games, found that psychological engagement was positively related to behavioural engagement including frequency and duration of game participation. The specific hypothesis put forward in this article is that:

H1: Psychological engagement in an online customer community website is positively associated with behavioural engagement.

\section{Perceived interactivity}

Mollen and Wilson (2010:921) describe perceived interactivity in the context of computer interactions as 'an experiential phenomenon that occurs when a user interacts with a website or other computer-mediated communication entities'. They note that perceived interactivity captures the degree to which the user perceives that theinteraction or communication is two-way, controllable, and responsive to their actions'. High levels of interactivity of online sites are associated with many benefits. It is known to help facilitate communication, enhancing consumer website experiences, and to help reduce the time and effort required for consumers to find information that they want on a website (Al-Shamaileh \& Sutcliffe 2013:1124; Huang, Zhu \& Zhou 2013:931). A review of literature shows that interactivity can be looked at from different perspectives, including from the system structural perspective and from the sociability perspective. Studies focusing on the structural perspective look at interactivity as a design feature within the domain of website usability (Zhang et al. 2014:1018; Zhao \& Lu 2012:826). Studies by Liao and Keng (2013:1849) as well as Mpinganjira (2014:593), referred to it as machine or system interactivity and contrasted it to human interactivity which focuses on the interaction between users of an online platform. In the case of social networking sites, the structural perspective calls for one to be cognisant of the fact that users interact through enabled technological features. The structural perspective entails looking at interactivity as a feature of technology. The extent to which interaction between the user and the technology is facilitated is thus core to understanding interactivity from the structural perspective.

Zhang et al. (2014:1018) observed that technological capabilities of websites can be looked at objectively or subjectively. They noted that objective assessment entails reflecting on objective properties independent of consumers, whilst subjective assessment entails reflecting on properties as perceived by users. In this article the focus is on interactivity as perceived by users. The aim is to capture perceptions on the extent to which interaction between the users and technology is facilitated. In looking at web-system interactivity, this article focuses on perceived control and synchronicity. This is in line with Palla, Tsiotsou and Zotos (2013:132) as well as Mollen and Wilson's (2010:921) assertions that there are three main dimensions of interactivity. They noted that one dimension has to do with two-way communication including feedback, the second being about synchronicity, and the third being about active control. In this article, two-way communication including feedback is explored under human interactivity. Studies by Zhao and Lu (2012:825) as well as Downes and McMillan (2000:157), noted that there are other many and varied facets to web interactivity, but identified perceived control and synchronicity as some of the important dimensions. In this article perceived control is defined as the ease with which one is able to perform the activities one wants to perform on the website. Synchronicity on the other hand focuses on the time dimension in one's interaction with the website. Thallmaier (2014:83) stated that synchronicity is 'a technical facet of interactivity which covers the question of how fast the website responds to customer input'.

Research on website users' experience notes that experience of high levels of website interactivity has a positive influence on user affective response, including satisfaction and overall attitude towards the website (Ahn, Hong \& Pedersen 2014:121; Ku \& Chen 2015:473; Teo et al. 2003:281). Hosseini and Fattahi (2014:319) found a positive relationship between website interactivity and optimal user experience. RodríguezArdura and Meseguer-Artola (2015:8) also found that website interactivity is associated with optimal experience. Taking cognisance of assertions by Brodie et al. (2011:258) that engagement as a psychological state results from interactive experiences, this article postulates that perceived web-system interactivity is positively associated with psychological engagement. Taking cognisance of perceived control and synchronicity as important dimensions of web-system interactivity, the specific hypotheses put forward are that:

H2: Perceived control on an online customer community website is positively associated with psychological engagement.

H3: Synchronicity on an online customer community website is positively associated with psychological engagement.

Whilst system interactivity in the case of websites focuses on the medium, human interactivity focuses on social interactions amongst the users. Zhang et al. (2014:1019) noted that high levels of interaction amongst users makes a website to be perceived as high on sociability. High levels of sociability can help users have a high sense of connectedness, that is, feelings of being connected to others (Zhao \& Lu 2012:830). In their study, Zhang et al. (2014:1025) found that perceived sociability is positively related to optimal user 
experience. Cheung et al. (2015:247) found that social interaction amongst online game players is positively associated with psychological engagement. Accordingly, this article hypothesises that:

H4: Human interactivity in an online customer community website is positively associated with psychological engagement.

\section{Proposed conceptual framework}

Figure 1 presents the conceptual framework proposed in this article to explain the relationship between interactivity in online customer community sites and consumer engagement. The model captures the hypotheses put forward in the article. It shows that perceived levels of active control, synchronicity and human interactivity are positively related to psychological engagement, which in turn is positively related to behavioural engagement.

\section{Methodology}

\section{Research approach and sampling}

This article is part of a larger study targeted at members of online customer communities. It was cross-sectional and quantitative in nature. Data were collected in Gauteng, South Africa, through a survey conducted amongst individuals who participate in discussions on online customer communities. Because of the lack of a sampling frame, a non-probability sampling method using convenience sampling technique was used to select respondents. Convenience sampling entails choosing respondents based on readiness in availability and the ability to provide required information (Hair et al. 2016:183).

\section{Measures}

All constructs of interest in the article as per the proposed model were operationalised as multi-item scales using scales adapted from past research studies. The adaptation of the scales was performed so as to ensure that the measures were in line with the purpose and context of the article. Active control was specifically measured using four items adapted from Yoo, Lee and Park (2010:93) and Wu and Wu (2006:96).

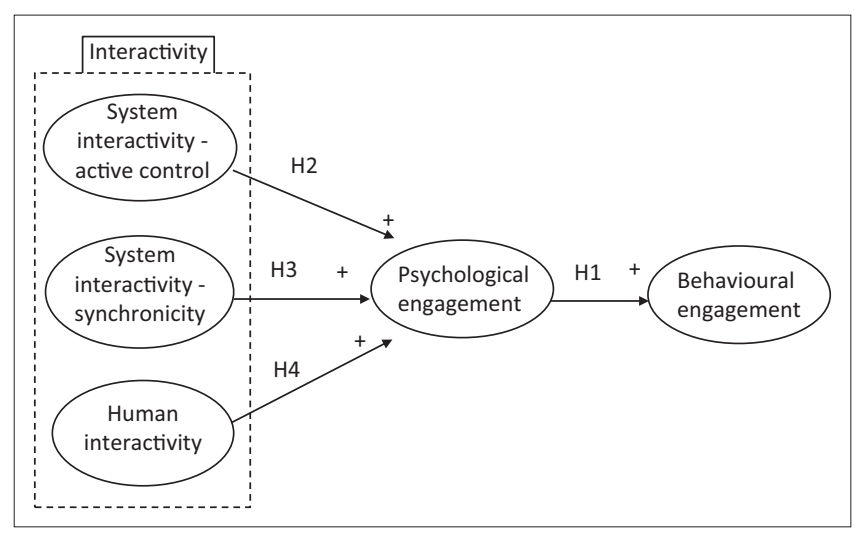

Source: Author's construction based on literature review

FIGURE 1: Proposed conceptual framework on the relationship.
Synchronicity was measured using four items adapted from Yoo et al. (2010:93), whilst human interactivity was measured using four items adapted from Zhao and Lu (2012:832). Psychological engagement, as well as behavioural engagement, was measured using four and three items respectively, adapted from Hollebeek et al. (2014:156). In the questionnaire, respondents were asked to indicate on a seven-point scale the extent to which they agreed with each item statement. The Likert scale was anchored on $1=$ very strongly disagree and $7=$ very strongly agree. The choice of the seven-point scale in this study was informed by assertions by Finstad (2010:108) who noted that seven-point scales provide more reliable measures of a participant's evaluation than a five-point scale.

\section{Data collection}

Data were collected with the help of trained research assistants belonging to a professional research company. The research assistants personally contacted respondents at varied places including shopping malls and asked them to participate in the study by completing the questionnaire. In order to ensure informed consent, only individuals who were 18 years and older were allowed to take part in the study. A screening question was used to identify individuals who were members of online customer communities. Eligible individuals who accepted the invitation to participate in the study, were asked to keep in mind one online customer community that they were members of when responding to questions in the questionnaire. By the end of the data collection period, a total of 303 usable responses were received. Forty-four point nine $(44.9 \%)$ per cent of the respondents were male, whilst $55.1 \%$ were female. The majority of the respondents, $(58.6 \%)$ were aged between 18 and 29 . Nearly $37 \%(36.8 \%)$ were aged between 30 and 40 years, and only $4.6 \%$ were aged above 40 . In terms of the highest level of education attained, the majority of the respondents, $32.8 \%$ had a post high school certificate or diploma, 30.1\% had a Bachelor's degree, $24.7 \%$ had a high school qualification, $10.5 \%$ had a postgraduate qualification, and only $2 \%$ indicated that their educational attainment was below high school. Respondents who had been part of their online customer community for a period of not more than one year accounted for $16.2 \%, 66.6 \%$ had been members for a period of between one and five years, and $17.2 \%$ had been members for over five years.

\section{Data analysis}

Structural equation modelling (SEM) was used to analyse the data. A two-step process advocated by Hair et al. (2010:730) was followed. The first step involved the assessment of the measurement model using confirmatory factor analysis, whilst the second step involved the examination of the structural paths for hypothesis testing. The assessment of the measurement model entailed the estimation of internal consistency of constructs, that is, construct reliability, the examination of model for fit, as well as testing the constructs for convergent and discriminant validity. Construct reliability 
was assessed using composite reliability (CR) coefficients as well as Cronbach's Alpha coefficients. As recommended by Hair et al. (2010:672), model fit was examined using multiple indices. The indices used include the normed chi-square value $\left(\chi^{2} / \mathrm{df}\right)$, Goodness of Fit Index (GFI), the Comparative Fit Index (CFI), the Tucker-Lewis Index (TLI), the Normative Fit Index (NFI) and the Root Mean Square Error of Approximation (RMSEA).

Convergent validity which measures the extent to which items making up a construct shares a high proportion of variance in common (Hair et al. (2010:709), was examined using factor loadings as well as Average Variance Extracted (AVE). Discriminant validity which examines the uniqueness of each construct in relation to others (Hair et al. (2010:710), was assessed by comparing the square root of AVE with inter-construct correlations, as well as comparing the AVEs with Maximum Shared Value (MSV).

\section{Results}

\section{Assessment of measurement model}

The results of the reliability tests presented in Table 1, show that the CR coefficients as well as the Cronbach's Alpha values were all above 0.70. According to Hair et al. (2010:710), construct reliability is supported by CR coefficients or Cronbach's Alpha values of 0.7 and above. The CR coefficients in this article ranged from 0.814 to 0.884 , with the lowest coefficient being for behavioural engagement and the highest being for human interactivity. The alpha values ranged from 0.814 for behavioural engagement to 0.882 for human interactivity.
Examination of model fit statistics showed a chi-square value of 266.920 with 124 degrees of freedom and a p-value of 0.000 resulting in a normed chi-square value of 2.153. According to Gaskin (2016:Online), a normed chi-square value of less than 3 indicates good model fit. Other fit indices also showed good fit. The GFI was 0.910 , the CFI was 0.956 , the TLI was 0.946 , the NFI was 0.922 . The PCLOSE was 0.029 , whilst the RMSEA was 0.062. According to Hair et al. (2010:667), model fit is evidenced by GFI, CFI, TLI and NFI values of $\geq 0.90$ as well as PCLOSE values of $\leq 0.05$ and RMSEA values of $\geq 0.08$.

With regard to convergent validity, the results in Table 1 show that individual item loadings on all constructs were greater than 0.5. Findings in Table 2 show that the AVE for each construct was greater than 0.5. As per Hair et al. (2010:709), factor loadings as well as AVEs of $\geq 0.5$ provide evidence of convergent validity. They further stated that discriminant validity is evidenced by AVEs that are greater than the MSVs, as well as the square root of AVEs that is greater than interconstruct correlations. The results in Table 2 show that both conditions were satisfied. By implication, the

TABLE 2: Correlation and validity tests.

\begin{tabular}{lccccc}
\hline Variable & AC & Sy & HI & PE & BE \\
\hline Active control (AC) & 0.802 & - & - & - & - \\
Synchronicity (Sy) & $0.684 *$ & 0.810 & - & - & - \\
Human interactivity (HI) & $0.452 *$ & $0.465 *$ & 0.811 & - & - \\
Psychological engagement (PE) & $0.571 *$ & $0.349 *$ & $0.570 *$ & 0.800 & - \\
Behavioural engagement (BE) & $0.452 *$ & $0.462 *$ & $0.728 *$ & $0.499 *$ & 0.770 \\
Average Variance Extracted (AVE) & 0.642 & 0.657 & 0.657 & 0.640 & 0.593 \\
Maximum Shared Value (MSV) & 0.468 & 0.468 & 0.530 & 0.326 & 0.530 \\
\hline Source: Calculated from survey data & & & & &
\end{tabular}

*, Correlation is significant $(p<0.05)$. Diagonal coefficients in bold are the square root of AVE.

TABLE 1: Descriptive, reliability and factor loadings.

\begin{tabular}{|c|c|c|c|c|c|}
\hline \multirow[t]{2}{*}{ Constructs and items } & \multicolumn{2}{|c|}{ Descriptive } & \multicolumn{2}{|c|}{ Reliability tests } & \multirow[t]{2}{*}{ Factor loadings } \\
\hline & Mean & SD & $\alpha$-value & $\begin{array}{l}\text { Composite } \\
\text { reliability (CR) }\end{array}$ & \\
\hline \multicolumn{6}{|l|}{ Active control (AC) } \\
\hline AC1 - While on the website I can choose freely what I want to see & - & - & - & - & 0.833 \\
\hline AC2 - I have a lot of control over my navigation at this website & - & - & - & - & 0.881 \\
\hline AC3 - I can easily filter the website information content & - & - & - & - & 0.864 \\
\hline AC4 - When navigating the website, I have control over what I can do on the site & 5.51 & 1.202 & 0.877 & 0.878 & 0.841 \\
\hline \multicolumn{6}{|l|}{ Synchronicity (Sy) } \\
\hline Sy1 - The website processes my input very quickly & - & - & - & - & 0.886 \\
\hline Sy2 - The pages load fast & 5.24 & 1.345 & 0.866 & 0.849 & 0.851 \\
\hline Sy3 - I am able to obtain the information I want without any delay & - & - & - & - & 0.930 \\
\hline \multicolumn{6}{|l|}{ Human interactivity (HI) } \\
\hline HI1 - Members of the community are very responsive to posts & - & - & - & - & 0.813 \\
\hline HI2 - One can always count on getting a lot of responses to posts & 5.4 & 1.222 & 0.882 & 0.884 & 0.883 \\
\hline $\mathrm{HI} 4$ - I receive responses to my requests posted on this website & & - & - & - & 0.876 \\
\hline \multicolumn{6}{|l|}{ Psychological engagement (PE) } \\
\hline PE1 - I feel very positive when I use this website & - & - & - & - & 0.811 \\
\hline PE2 - Using this website makes me contented & 5.77 & 1.049 & 0.875 & 0.877 & 0.873 \\
\hline PE3 - I feel fulfilled when I use this website & - & - & - & - & 0.883 \\
\hline PE4 - I'm happy to use this website & - & - & - & - & -0.846 \\
\hline \multicolumn{6}{|l|}{ Behavioural engagement (BE) } \\
\hline BE1 - I spend considerable time reading postings on this website & - & - & - & - & 0.853 \\
\hline BE2 - I pay special attention to postings on this website & 5.35 & 1.211 & 0.814 & 0.814 & 0.874 \\
\hline BE3 - I regularly provide suggestions on queries posted on this site & - & - & - & - & 0.834 \\
\hline
\end{tabular}

Source: Calculated from survey data 
results indicate that each construct was distinct from the others with items relating more to their own factor than to others (Gaskin 2016:Online).

Overall, the findings in this article relating to reliability tests, model fit statistics, convergent and discriminant validity tests provide evidence that the measurement model was satisfactory.

\section{Hypotheses testing}

Table 3 present the results of the hypotheses tests. According to the results, psychological engagement was found to be positively and significantly associated with behavioural engagement, $\beta=0.549, p=0.000$. The results thus provide empirical support for hypothesis H1. Examination of the interactivity related path coefficients show that all three dimensions of interactivity were significantly associated with psychological engagement. The standardised path coefficients were $\beta=0.502, p=0.000$ for active control; $\beta=0.189, p=0.189$ for synchronicity and $\beta=0.467, p=0.000$ for human interactivity. Based on these results, H2, H3 as well as $\mathrm{H} 4$ are accepted. A summary of the results from the hypotheses tests is also illustrated in Figure 2. The results further show that psychological engagement is able to explain 30\% of the variance in behavioural engagement, whilst the three dimensions of interactivity were able to collectively explain $51 \%$ of the variance in psychological engagement.

\section{Discussion and implications}

Consumer engagement is recognised as a fundamental construct in relationship marketing literature (Dwivedi 2015:107). This article aimed at extending knowledge on consumer engagement by focusing on users of online customer

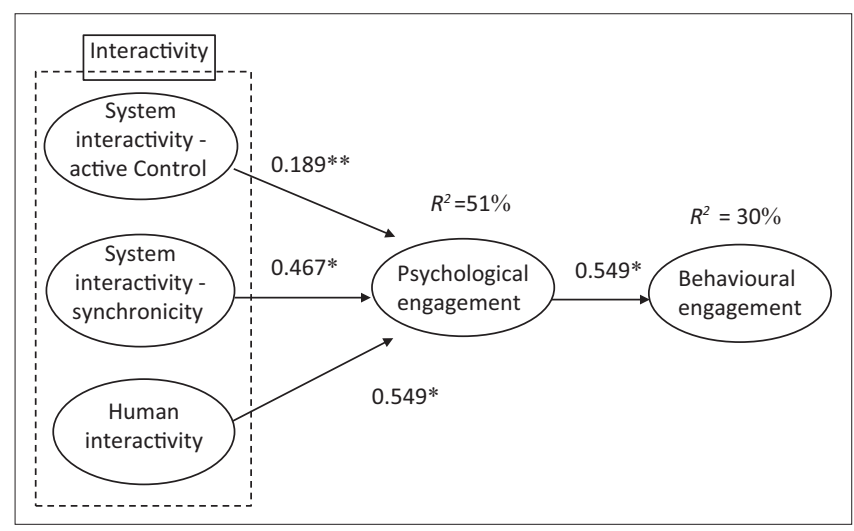

Source: Author's construction based on literature review and results

$*, p<0.001 ; * *, p<0.05$.

FIGURE 2: Results of the analysis of the structural model. community sites. This is in line with calls from researchers including Hollebeek et al. (2014:161) as well as Gambetti and Graffigna (2010:820) for studies aimed at understanding consumer engagement in varied contexts, including engagement using non-traditional media. Examination of levels of psychological and behavioural engagement amongst the users of the online customer community sites showed that such sites can be a good platform for facilitating user engagement. The overall mean value for psychological engagement was found to be 5.77, whilst that of behavioural engagement 5.35. The findings are consistent with assertions by Kilkku (2011:Online) who opined that the new media provides great opportunities for enhanced consumer engagement.

Examination of the relationship between psychological engagement and behavioural engagement showed that psychological engagement is strongly associated with behavioural engagement $(\beta=0.549 ; p=0.000)$. These findings are in line with arguments in consumer behavioural research including those of Hollebeek et al. (2014:160) that note the importance of examining consumers' affective condition in order to understand actual behaviour.

Apart from examining levels of engagement and relationship between different engagement types, the article also examined the role of interactivity in explaining user engagement in online customer community sites. Its findings show that higher levels of interactivity of online customer community sites are positively associated with psychological engagement. The findings are in line with assertions by Rodríguez-Ardura and Meseguer-Artola (2015:8), noting that interactivity is an important service quality attribute of web services, and that success in providing high service quality helps enhance optimal experience. Taking cognisance of the fact that on online social networking platforms such as online customer communities, interaction involves human and system interaction as well as human and human interaction. In looking at interactivity, the article looked at system-related interactivity dimensions as well as human interactivity. The findings showed that whilst all dimensions of interactivity were significantly associated with psychological engagement, the system interactivity dimension of active control had a stronger association $(\beta=0.502 ; p=0.000)$ followed by human interactivity $(\beta=0.467 ; p=0.000)$. Synchronicity had the lowest level of association $(\beta=0.189 ; p=0.018)$.

The findings in this article are of significant theoretical and managerial importance. These are outlined in the following sections.

TABLE 3: Effects of interactivity on engagement.

\begin{tabular}{|c|c|c|c|c|c|}
\hline Predicted variable & Predictor variable & $\begin{array}{c}\text { Standardised regression } \\
\text { coefficient }\end{array}$ & SE & $t$-value & $p$-value \\
\hline \multirow[t]{3}{*}{ Psychological engagement } & Active control & 0.502 & 0.076 & 5.936 & 0.000 \\
\hline & Synchronicity & 0.189 & 0.064 & 2.366 & 0.018 \\
\hline & Human interactivity & 0.467 & 0.057 & 7.100 & 0.000 \\
\hline Behavioural engagement & Psychological engagement & 0.549 & 0.074 & 7.654 & 0.000 \\
\hline
\end{tabular}

Source: Calculated from survey data 


\section{Theoretical implications}

This article contributes to theory in four important ways. Firstly, it extends literature on consumer engagement by examining it in the context of social media. Although marketers acknowledge the importance on consumer engagement and the need for harnessing it, the concept has not received much scholarly attention (Cheung et al. 2011:2; Dwivedi 2015:101). Several scholars who have examined the concept of engagement in marketing have done so by focusing on brand engagement. To the best of the author's knowledge, the present article is amongst the first ones to examine engagement in the context of online customer communities. It thus contributes to enhancing knowledge about engagement in a different context.

Secondly, by focusing on not only behavioural engagement but also psychological engagement, the article helps fill the gap in existing literature where engagement is often investigated from a single perspective. Chandler and Lusch (2014:9) called for the integration of different ways of conceptualising engagement in order to account more for the influence of context on engagement. Results of the validity tests conducted in this article, particularly findings on discriminant validity, show that psychological and behavioural engagement, are unique constructs of consumer engagement and that there is significant association between the two forms of engagement.

Thirdly, it adds new insights into consumer engagement literature by uncovering the significant role played by perceived interactivity in influencing psychological engagement of users of online customer community sites. Brodie et al. (2011:258) pointed to the need to examine interactive experiences with objects of engagement in order to explain engagement as a psychological state. In this article, three dimensions of interactivity associated with online customer communities namely active control, synchronicity and human interactivity were examined, and all were found to have significant influence on psychological engagement. The findings point to the importance of focusing on system-related interactivity as well as human-related interactivity in uncovering ways of enhancing psychological engagement in online customer communities.

Lastly, it empirically shows the applicability of the SDL of marketing in uncovering value in online customer communities. The SDL emphasises the importance of service as a source of value. On the part of users of online customer communities, system and human interactivity provide opportunity for enhanced functional as well as experiential value. This is because system interactivity helps reduce time and effort required when making use of technology (Huang et al. 2013:931). Human interactivity on the other hand, helps promote responsiveness to content including requests for information posted on online platforms (Yoo et al. (2010:94). Perceived value is known to be associated with favourable customer response (Dovaliene et al. 2015:663). In this article, this is empirically evidenced by findings showing the positive influence that interactivity has on user-affective response, that is psychological engagement.

\section{Managerial implications}

From a practical perspective, the findings in this article have significant implications for the management of online customer community sites. Firstly, it is important for managers to realise that online customer community sites can offer great opportunities for enhanced consumer engagement. Managers can specifically use such sites to facilitate psychological as well as behavioural engagement. Relationship marketing literature notes the important role that customer engagement plays in influencing customer retention (Brodie et al. 2013:105). With the growing use of social networking sites by organisations to facilitate customer to customer as well as customer to firm interaction, competition for users on such sites will increasingly become a matter of great concern to managers of such sites. The ability to stimulate high levels of psychological and behavioural engagement, can thus offer managers great opportunities to effectively differentiate themselves from competing sites.

The fact that levels of engagement vary from one user to another, points to the usefulness of the concept in segmenting users of their online customer community sites. A good understanding of the sites' most and least engaged users and their relative proportion, can be helpful for managers of online customer community sites to identify the appeal of their value proposition to different types of users of their sites. The ability to do this requires that managers of online customer community sites invest in measuring user engagement levels. This article provides measurement scales that managers can use in assessing the different manifestations of engagement. In measuring levels of engagement, managers need to take cognisance of the fact that the intensity of engagement is likely to vary over time. Managers thus need to take special interest in uncovering possible factors that may help explain variations in user engagement levels over time. Special focus needs to be placed on changes in engagement levels associated with system changes, as well as changes in the levels of human-to-human interaction over time.

Findings in this article specifically point to the need to pay attention to both system-related and human-related levels of interactivity in order for managers to facilitate positive user engagement. With regard to system interactivity, managers need to specifically pay attention to their site design issues. The system needs to be designed with users in focus. It needs to be engineered to facilitate positive user experience by ensuring that users are able to take active control when navigating the community site, as well as ensuring that the community site is highly responsive, that is, paying attention to synchronicity. Active control demands that sites be designed in such a manner that users can easily search and interact with content of interest. Active control on online customer community sites can be enhanced by ensuring that 
users are able to easily filter website information content, and that they have options on the way content can be viewed.

As for synchronicity, managers need to take cognisance of the fact that the length of time a website takes to respond to user commands can have a significant impact on user experience. In order to ensure good user experience, managers need to monitor the level of system responsiveness to commands. Factors that may negatively impact on synchronicity include heavy use of multimedia files and, or, growing numbers of users without a corresponding increase in available band width. Managers thus need to ensure that available bandwidth is able to support ongoing activities on their sites.

Lastly, findings in this article showing the positive influence of high levels of human interactivity on user engagement, point to the need for managers of online customer community sites to focus on ways in which they can promote user-to-user interaction on their sites. This requires that managers find ways of creating and promoting value-adding conversation on their sites. Promotion of value-adding conversations necessitates a good understanding of topics that are likely to be appealing to members of an online customer community. Managers can monitor the popularity of different discussion topics on their sites over time in terms of the ability to attract significant volumes in comments, as well as in the number of unique members commenting on given topics. The collection of such information over time can provide managers with insights on discussion topics they may need to prioritise when there is the need to facilitate more member interaction.

\section{Limitations and suggestions for future research}

Whilst this article has significant theoretical and practical implications, it is not without limitations. Its limitations include the fact that it is based on a sample of members of online customer communities drawn from a limited geographical area, namely Gauteng. Furthermore, the sample was drawn using a convenience sampling method. As a result, the findings may not be generalised to the wider population of online customer community members in South Africa. Future research using samples drawn from other geographical areas as well as those using probability sampling techniques, is thus recommended. Such research can help test the applicability of the proposed model in different contexts.

Another limitation relates to the fact that in looking at antecedents of engagement, the article focused on only three dimensions of interactivity. The main reason for focusing on the three chosen dimensions, is because they capture both the system and social perspective of interactivity. Furthermore, the three dimensions are in line with those found in past research including studies by Palla et al. (2013:132) as well as Mollen and Wilson (2010:921). Whilst this is so, some studies take cognisance of the fact that other studies argue for more dimensions. Future research can thus explore the concept of interactivity in the context of online customer communities further, so as to uncover additional dimensions. Such studies can help deepen the levels of understanding of the role of interactivity in influencing user engagement. Future studies can also look at factors other than interactivity that can help in understanding user engagement in online customer communities.

\section{Conclusions}

This article sought to understand user engagement in the context of online customer communities and the role of interactivity in influencing this. Based on the findings, several conclusions can be drawn. Firstly, user engagement in online communities can manifest itself in different related ways. The findings in this article specifically show that users of online communities can be psychologically and behaviourally engaged. The level of psychological engagement was found to be significantly associated with the level of behavioural engagement. The findings point to the existence of a strong relationship between online customer community users' affective state and their behavioural response.

With regard to interactivity, the findings show that the concept of interactivity in the context of online customer communities can be viewed from a multidimensional perspective. Interaction on such sites involves the platform itself, as well as other members of the community. High levels of human interactivity as well as system interactivity as evidenced by active control and synchronicity, exert a significant positive influence on levels of psychological engagement amongst users of online customer communities.

Taking cognisance of the growing use of social media by individuals and companies for purposes related to commerce, there is a need for managers of customer social networking sites such as online customer communities to find effective ways in which they can make their sites appealing to users. This article contributes to knowledge on how managers can do this by specifically focusing on the levels of consumer engagement.

\section{Acknowledgements Competing interests}

The author declares that she has no financial or personal relationships which may have inappropriately influenced her in writing this article.

\section{References}

Ahn, T., Hong, M. \& Pedersen, P.M., 2014, 'Effects of perceived interactivity and web organization on user attitudes', European Sport Management Quarterly 14(2), 111-128. http://dx.doi.org/10.1080/16184742.2014.880496

Al-Shamaileh, O. \& Sutcliffe, A.G., 2013, 'Website interactivity and repeated exposure, what influences user experience?', Journal of Universal Computer Science 19(8), 1123-1139.

Ángeles Oviedo-García, M., Muñoz-Expósito, M., Castellanos-Verdugo, M. \& SanchoMejías, M., 2014, 'Metric proposal for customer engagement in Facebook', Journal of Research in Interactive Marketing 8(4), 327-344. http://dx.doi. org/10.1108/JRIM-05-2014-0028

Appelbaum, A., 2001, 'The constant customer', Gallup Management Journal 1(2), 5. 
Bowden, J.L.H., 2009, 'The process of customer engagement: A conceptual framework', Journal of Marketing Theory and Practice 17(1), 63-74. http://dx.doi. ramework', Journal of Marketing Theor
org/10.2753/MTP1069-6679170105

Brodie, R.J., Hollebeek, L.D., Juric, B. \& Ilic, A., 2011, 'Customer engagement: Conceptual domain, fundamental propositions, and implications for research', Journal of Service Research 14(3), 252-271. http://dx.doi.org/10.1177/1094670511411703

Brodie, R.J., Ilic, A., Juric, B. \& Hollebeek, L., 2013, 'Consumer engagement in a virtual brand community: An exploratory analysis', Journal of Business Research 66(1) 105-114. http://dx.doi.org/10.1016/j.jbusres.2011.07.029

Cabiddu, F., De Carlo, M. \& Piccoli, G., 2014, 'Social media affordances: Enabling customer engagement', Annals of Tourism Research 48, 175-192. http://dx.doi. org/10.1016/j.annals.2014.06.003

Cellary, W., 2015, 'e-Service-dominant Logic', Procedia Manufacturing 3, 3629-3635. http://dx.doi.org/10.1016/j.promfg.2015.07.747

Chandler, J.D. \& Lusch, R.F., 2014, 'Service systems a broadened framework and research agenda on value propositions, engagement, and service experience', Journal of Service Research 18(1), 6-22. http://dx.doi.org/10.1177/1094670514537709

Cheung, C., Lee, M. \& Jin, X., 2011, 'Customer engagement in an online social platform: A conceptual model and scale development', in Conference Proceedings of the Thirty Second International Conference on Information Systems, Shangh of the December 2011, ICIS. Viewed 28 January 2016, from http://citeseerx.ist.psu.edu/ viewdoc/download?doi=10.1.1.231.8561\&rep=rep1\&type=pdf

Cheung, C.M., Shen, X.L., Lee, Z.W. \& Chan, T.K., 2015, 'Promoting sales of online games through customer engagement', Electronic Commerce Research and Applications 14(4), 241-250. http://dx.doi.org/10.1016/j.elerap.2015.03.001

Dovaliene, A., Masiulyte, A. \& Piligrimiene, Z., 2015, 'The relations between customer engagement, perceived value and satisfaction: The case of mobile applications', Procedia-Social and Behavioral Sciences 213, 659-664. http://dx.doi.org/10.1016/j. sbspro.2015.11.469

Downes, E.J. \& McMillan, S.J., 2000, 'Defining interactivity a qualitative identification of key dimensions', New Media \& Society 2(2), 157-179. http://dx.doi. org/10.1177/14614440022225751

Dwivedi, A., 2015, 'A higher-order model of consumer brand engagement and its impact on loyalty intentions', Journal of Retailing and Consumer Services 24, 100-109. http://dx.doi.org/10.1016/j.jretconser.2015.02.007

Finstad, K., 2010, 'Response interpolation and scale sensitivity: Evidence against 5-point scales', Journal of Usability Studies 5(3), 104-110.

Gambetti, R. \& Graffigna, G., 2010, 'The concept of engagement', Internationa Journal of Market Research 52(6), 801-826. http://dx.doi.org/10.2501/ S147078531020166

Gaskin, J., 2016, 'Confirmatory factor analysis', viewed 18 January 2016, from http:// statwiki.kolobkreations.com/index.php?title=Confirmatory_Factor_Analysis

Hair, J., William, C., Barry, J. \& Anderson, R., 2010, Multivariate data analysis: A global perspective, 7th edn., Prentice Hall, Upper Saddle River,NJ.

Hair Jr., J.F., Celsi, M.W., Money, A.H., Samouel, P. \& Page, M.J., 2016, Essentials of business research methods, 3rd edn., Routledge, New York.

Harwood, T. \& Garry, T., 2015, 'An investigation into gamification as a customer engagement experience environment', Journal of Services Marketing 29(6/7), 533-546. http://dx.doi.org/10.1108/JSM-01-2015-0045

Hollebeek, L.D., 2013, 'The customer engagement/value interface: An exploratory investigation', Australasian Marketing Journal 21(1), 17-24. http://dx.doi. org/10.1016/j.ausmj.2012.08.006

Hollebeek, L.D., Glynn, M.S. \& Brodie, R.J., 2014, 'Consumer brand engagement in social media: Conceptualization, scale development and validation', Journal of Interactive Marketing 28(2), 149-165. http://dx.doi.org/10.1016/j.intmar.2013.12.002

Hosseini, S.M. \& Fattahi, R., 2014, 'Databases' interface interactivity and user selfefficacy: Two mediators for flow experience and scientific behavior improvement' Computers in Human Behavior 36, 316-322. http://dx.doi.org/10.1016/j. chb.2014.03.014

Huang, M., Zhu, H. \& Zhou, X., 2013, 'The effects of information provision and interactivity on e-tailer websites', Online Information Review 37(6), 927-946. http://dx.doi.org/10.1108/OIR-07-2012-0117
Kilkku, V., 2011, 'Social media is an essential tool for service-dominant logic', viewed 28 January 2016, from http://www.kilkku.com/blog/2011/08/social-media-is-anessential-tool-for-service-dominant-logic/

Ku, E.C. \& Chen, C.D., 2015, 'Cultivating travellers' revisit intention to e-tourism service: The moderating effect of website interactivity', Behaviour \& Information Technology 34(5), 465-478. http://dx.doi.org/10.1080/0144929X.2014.978376

Kuzgun, E. \& Asugman, G., 2015, 'Value in services-A service dominant logic perspective', Procedia-Social and Behavioral Sciences 207, 242-251. http://dx.doi. org/10.1016/j.sbspro.2015.10.093

Liao, T.H. \& Keng, C.J., 2013, 'Online shopping delivery delay: Finding a psychological recovery strategy by online consumer experiences', Computers in Human Behavio 29(4), 1849-1861. http://dx.doi.org/10.1016/j.chb.2013.03.004

Liu, Y., Pu, B., Guan, Z. \& Yang, Q., 2015, 'Online customer experience and its relationship to repurchase intention: An empirical case of online travel agencies in China', Asia Pacific Journal of Tourism Research 1-22. http://dx.doi.org/10.1080/ 10941665.2015.1094495

Manchanda, P., Packard, G. \& Pattabhiramaiah, A., 2015, 'Social dollars: The economic impact of customer participation in a firm-sponsored online customer community', Marketing Science 34(3), 367-387. http://dx.doi.org/10.1287/mksc.2014.0890

Mollen, A. \& Wilson, H., 2010, 'Engagement, telepresence and interactivity in online consumer experience: Reconciling scholastic and managerial perspectives', Journal of Business Research 63(9), 919-925. http://dx.doi.org/10.1016/j. jbusres.2009.05.014

Mpinganjira, M., 2014, 'The influence of online store interactivity on customers' shopping experience: An empirical investigation', Journal of Contemporary Management 11, 593-612.

Palla, P., Tsiotsou, R.H. \& Zotos, Y.T., 2013, 'Is website interactivity always beneficial? An elaboration likelihood model approach', Advances in Advertising Research 4, 131-145. http://dx.doi.org/10.1007/978-3-658-02365-2_10

Rodríguez-Ardura, I. \& Meseguer-Artola, A., 2015, 'E-learning continuance: The impact of interactivity and the mediating role of imagery, presence and flow', Information \& Management, viewed 6 February 2016, from http://ac.els-cdn. com/S0378720615001317/1-s2.0-S0378720615001317-main.pdf? tid $=142 \mathrm{f} 6 \mathrm{ca} 4-\mathrm{d} 184-11 \mathrm{e} 5-8040-00000 \mathrm{aacb} 35 \mathrm{~d} \& \mathrm{acdnat}=1455280271 \_3 \mathrm{c} 15 \mathrm{f} 824 \overline{6}$ $60 \mathrm{bf3} 3 \mathrm{~b} 3 \mathrm{~d} 4 \mathrm{ef} 78 \mathrm{~d} 42 \mathrm{afd} 4 \mathrm{~d} 5$

Sashi, C.M., 2012, 'Customer engagement, buyer-seller relationships, and social media', Management Decision 50(2), 253-272. http://dx.doi.org/10.1108/00251 741211203551

Teo, H.H., Oh, L.B., Liu, C. \& Wei, K.K., 2003, 'An empirical study of the effects of interactivity on web user attitude', International Journal of Human-Computer Studies 58(3), 281-305. http://dx.doi.org/10.1016/S1071-5819(03)00008-9

Thallmaier, S.R., 2014, Customer co-design: A study in the mass customization industry, Springer, Leipzig, Germany.

Van Doorn, J., Lemon, K.N., Mittal, V., Nass, S., Pick, D., Pirner, P., et al., 2010, 'Customer engagement behavior: Theoretical foundations and research directions', Journal ofService Research13(3),253-266. http://dx.doi.org/10.1177/1094670510375599

Vargo, S.L. \& Lusch, R.F., 2004, 'Evolving to a new dominant logic for marketing', Journal of Marketing 68(1), 1-17. http://dx.doi.org/10.1509/jmkg.68.1.1.24036

Wu, G. \& Wu, G., 2006, 'Conceptualizing and measuring the perceived interactivity of websites', Journal of Current Issues \& Research in Advertising 28(1), 87-104. http://dx.doi.org/10.1080/10641734.2006.10505193

Yoo, W.S., Lee, Y. \& Park, J., 2010, 'The role of interactivity in e-tailing: Creating value and increasing satisfaction', Journal of Retailing and Consumer Services 17(2), 89-96. http://dx.doi.org/10.1016/j.jretconser.2009.10.003

Zhang, H., Lu, Y., Gupta, S. \& Zhao, L., 2014, 'What motivates customers to participate in social commerce? The impact of technological environments and virtual customer experiences', Information \& Management 51(8), 1017-1030. http:// dx.doi.org/10.1016/j.im.2014.07.005

Zhao, L. \& Lu, Y., 2012, 'Enhancing perceived interactivity through network externalities: An empirical study on micro-blogging service satisfaction and continuance intention', Decision Support Systems 53(4), 825-834. http://dx.doi. org/10.1016/j.dss.2012.05.019 